smaller within six months. This has led us to consider using stents to maintain the patency of the fenestration. In an experimental study on mongrel dogs we showed that this was technically feasible. Meanwhile stenting of an atrial fenestration has been performed in another centre with a good clinical result (Dr De Giovanni; Birmingham; personal communication).

We consider creating a percutaneous fenestration as a temporary treatment in Fontan patients with PLE who have no treatable cause for systemic venous hypertension (conduit stenosis, pulmonary artery stenosis, arrhythmia, ventricular failure) and when conventional medical treatment (diuretics, steroids) is ineffective. It does not appear to offer a long-lasting solution but buys time to improve the patient's general condition before Fontan take-down or heart transplantation is performed.

$$
\begin{array}{r}
\text { LUC MERTENS } \\
\text { MARC GEWILLIG } \\
\text { Paediatric Cardiology, } \\
\text { University Hospital Gasthuisberg, } \\
\text { Herestraat 49, } \\
\text { B } 3000 \text { Leuven, } \\
\text { Belgium }
\end{array}
$$

1 Gewillig M, Mertens L, Stockx L. Percutaneous fenestration of the atrial septum with a stent. Cor Europeaum. Eur $\mathcal{f}$ Cardia Interventions 1995;4:122-5.

\section{Coronary Palmaz-Schatz stent implan-} tation in acute myocardial infarction

SIR,-Neumann et al are to be applauded for reporting that coronary stenting is an effective safe adjunct to direct percutaneous transluminal coronary angioplasty (PTCA) for acute myocardial infarction. ${ }^{1}$ This finding paves the way to a randomised evaluation. Their pilot study clearly lacks power to assess the clinical impact of pre-existing target vessel thrombus on reocclusion. It is, however, residual thrombus after balloon PTCA (seen in $36 \%$ of their cases) that gives greater concern. Moreover, without coronary ultrasound or angioscopy, it may sometimes be difficult to determine whether such residual thrombus is due to covert dissection, intimal disruption, or is a reflection of a highly thrombogenic milieu despite seemingly optimum dilatation and flow. When the latter is thought to apply, we are naturally hesitant to stent, even though we would routinely use adjunctive intra-aortic balloon counterpulsation to optimise coronary perfusion. ${ }^{2}$ Like others, we sometimes resort to a period of intracoronary thrombolysis using an infusion catheter, but the results are unpredictable. ${ }^{3}$ In our experience, the most thrombogenic patients tend to be those undergoing not primary PTCA but rescue PTCA, particularly if they seem to be resistant to several doses of intravenous thrombolysis which may have induced a procoagulant state. ${ }^{4}$ It remains to be seen whether the platelet glycoprotein IIb/IIIa receptor antibody (c7E3 Fab) will have a major role in this difficult situation.

MICHAEL S NORELL

Department of Cardiology, Hull Royal Infirmary Hull HU3 $27 Z$

1 Neumann F-J, Walter H, Richardt G, Schmit C, Schömig A. Coronary Palmaz-Schat stent implantation in acute myocardial infarction. Heart 1996;75:121-6.

2 Ohman EM, George BS, White CW, Kern MI, Gurbel PA, Freedman RJ, et al for the
Randomized IABP Study Group. Use of aortic counterpulsation to improve sustained coronary artery patency during acute myocardial infarction. Results of a randomized trial. Circulation 1994;90:792-9.

3 Gulba DC, Daniel WG, Simon R, Jost S, Barthels M, Amende I, et al. Role of thrombolysis and thrombin in patients with acute coronary occlusion during percutaneous coronary occlusion during percutaneous Cardiol 1990;16:563-8.

4 Fitzgerald DJ, Catella F, Roy L, Fitzgerald GA. Marked platelet activation in vivo after intravenous streptokinase in patients with 1988;77:142-50.

5 The EPIC Investigators. Use of a monoclonal antibody directed against the platelet glycoprotein IIb/IIIa receptor in high-risk coronary angioplasty. $N$ Engl $\mathcal{f}$ Med 1994;330:

This letter was shown to the authors, who reply as follows:

SIR,-As Dr Lim and Dr Norell correctly point out, coronary thrombus after balloon PTCA is a problem, particularly when a stent is thought to be needed. Clearly, our study does not have sufficient power to disprove their suggestion that residual thrombus before stent placement increases the risk of subsequent stent thrombosis in acute myocardial infarction. In fact, the trend we found points towards an increased risk Nevertheless, our data show that stenting in the presence of residual thrombus does not carry a prohibitive risk of subacute sten thrombosis. Even with the help of coronary ultrasound it may be difficult to distinguish between a primarily thrombogenic milieu and intimal disruption as the major mechanism for coronary thrombus formation. Ou findings suggest that a coronary stent should be implanted in any case if needed and although we cannot provide hard data to support our recommendation, we believe that adjunctive antiplatelet therapy should be given. We agree with $\mathrm{Lim}$ and Norell that the newly developed platelet glycoprotein IIb/IIIa receptor antagonists deserve serious consideration for this purpose.

FRANZ-JOSE HANNA WALTER ALBERT SCHÖMIG

1 Medizinische Klinik und Poliklinik rechts der Isar Ismaninger Strasse 22, 81675 Munich,

Germany

Significance of perfusion of the infarct related coronary artery for susceptibility to ventricular tachyarrhythmias in patients with previous myocardial infarction

SIR,-Huikuri et al highlighted a very important aspect of current cardiology-that is, risk assessment for sudden death after myocardial infarction (MI). ${ }^{1}$ The quest for a single test with a high predictive power has been the holy grail of cardiology for the pas 10 years.

The risk factors assessed so far, including reduced heart rate variability, baroreceptor sensitivity, signal averaged electrocardiogram (ECG), and ejection fraction, are poor predictors when used alone but were additive in combination. Farrell et al found that heart rate variability and signal averaged ECG offered the best sensitivity and specificity. ${ }^{2}$ Even in this "high risk" group between $70 \%$ to $85 \%$ of patients will be event-free over several years of follow up, hence the need for a single test with a high predictive power.

The study of Huikuri et al implies that revascularisation of the infarct related artery will reduce ventricular arrhythmias. However, we are not told of the number of previous infarctions in the groups or whether a ventricular aneurysm was present: revascularisation would only supress $50 \%$ of inducible ventricular tachycardias (VT) in the presence of a large myocardial scar (O'Rourke ${ }^{3}$ ). Although the time elapsed after myocardial infarction is comparable in Huikuri et al's two patient groups, the samples are skewed and the use of the median and of non-parametric tests might have shown that the groups were not comparable. The emphasis placed on electrophysiologica studies is not justified because most studies suggest that this is a poor predictor of sudden death in uncomplicated infarctions. Kowey et al in a meta-analysis found no difference in arrhythmic events between those who had inducible VT and those who did not. ${ }^{4}$

Vatterott et al showed that the best predictor of late potentials on a signal averaged ECG was a closed artery; the next best predictor was a previous $\mathrm{MI}{ }^{5}$ This reduction in the number of late potentials could also be achieved by angioplasty between days 6 and 15-that is, beyond the period of myocardial salvage. ${ }^{6}$ Hohnloser et al showed that this benefit translates into event-free survival. ${ }^{7}$ In their study patients underwent revascularisation if they had objective evidence of ischaemia. The most powerful predictors of arrhythmias were a closed artery $P<0.00002$, left ventricular dysfunction $P<0.003$, and late potentials $P<0.04$ Even when these three risk factors were summed they had a positive predictive power of only $50 \%$. Undertaking coronary angiography and revascularisation has tremendous implications for costs and time. A better cost benefit approach may be to use a less sensitive test but treat those at risk with amiodarone. This is the basis of the eagerly awaited European and Canadian trials.

8 West Green Close

1 Huikuri HV, Koistinen MJ, Airaksinen KEJ Ikäheimo MJ. Significance of perfusion of the infarct related coronary artery for susceptibility to ventricular tachyarrhythmias in patients with previous myocardial infarction. Heart 1996;75:17-22.

2 Farrell TG, Bashir Y, Cripps T, et al. Risk stratification for arrhythmic events in postinfarction patients based on heart rate variability, ambulatory electrocardiographic variables and the signal averaged electrocardiogram. F Am Coll Cardiol 1991;18:687-97.

3 O'Rourke RA. Role of myocardial revascularisation in sudden cardiac death. Circulation 1992;85(I suppl):112-7.

4 Kowey PR, Taylor JE, Rials SJ. Does programmed stimulation really help in the evaluation of patients with nonsustained ventricular tachycardia? Results of a meta analysis. Am Heart $f$ 1992;123:481-5.

5 Vatterott PJ, Hammil SC, Bailey KR, et al. atterot PJ, Hammil SC, Bailey KR, et al. Late potentials on signal-averaged electrocardiograms and patency of the infarct-related artery in survivors of acute myocardial infaret

Aange RA, et al. Effect of coronary angioplasty on late poten to two weeks after acute myocard infarcion.

7 Hohnloser SH, Franck P, Klingenheben T, et al. Open infarct artery, late potentials, and other prognostic factors in patients after acule mocardial infarction in the thrombolytic era. A prospective trial. Circulation 
This letter was shown to the authors, one of whom responds as follows:

SIR,-It is true that the positive predictive accuracy of all the available tests for predicting the arfhythmic death in patients after myocardial infarction is low and that more specific tests are needed. Because our study was cross sectional it cannot give information on the predictive accuracy of an occluded infarct-related artery. However, it was the first study to show the beneficial effects of perfusion of an old infarct scar on the electrophysiological substrate. We agree that in this type of cross sectional comparison it is difficult to achieve 1:1 matching of all the factors that may influence arrhythmogenesis. None the less the study was specifically designed to match the patient group for ejection fraction, wall motion abnormalities (including presence of ventricular aneurysm), and number of previous infarctions ${ }^{1}$ (tables 1 and 2).

No conclusions about the benefits of revascularisation can be based on the data of our study, ${ }^{1}$ but we hope that a randomised prospective trial that is underway will give insights into the potential beneficial effect of angioplasty of the occluded infarct artery on the arrhythmic substrate.

HEIKKI V HUIKURI
Division of Cardiology
Department of Medicine
Oulu University,
Central Hospital,
90220 Oulu,
Finland

1 Huikuri HV, Koistinen MJ, Airaksinen KEJ Ikäheimo MJ. Significance of perfusion of the infarct related coronary artery for suscep tibility to ventricular tachyarrhythmias in patients with previous myocardial infarction. Heart 1996;75:17-22.

Non-surgical ablation of the ventricular septum for the treatment of hypertrophic cardiomyopathy

SIR,-We read with interest Professor Oakley's erudite review of the natural course and treatment of hypertrophic cardiomyopathy. ${ }^{1}$ Sadly, she regards the development of non-surgical ablation of the ventricular septum at our hospital as an ingenious but unimportant endeavour. She observes that symptoms, gradients, and outlook are unrelated in hypertrophic cardiomyopathy; that surgical relief of outflow tract obstruction does not improve outcome and may impair overall left ventricular function; and finally that the natural course of hypertrophic cardiomyopathy is towards a reduction in outflow tract obstruction with time as left ventricular impairment and dilatation progress.

Undoubtedly, the degree of obstruction of the outflow tract does not correlate well with either symptomatic status or outlook within populations of patients with hypertrophic cardiomyopathy. None the less, when an individual patient has a large outflow gradient and symptoms that correlate with such obstruction-namely, exertional angina, dyspnoea, and syncope-an association between outflow tract obstruction and symptoms seems beyond any doubt. Furthermore, there is evidence that these symptoms are improved by manoeuvres that reduce the obstruction, ${ }^{2}$ including our new technique. ${ }^{3}$ As there is no prospective randomised evidence to suggest that surgical relief of outflow tract obstruction either prolongs or shortens life, it is important that both surgical and non-surgical myocardial reduction are performed for the palliation of symptoms. We have not suggested that survival benefit accrues from non-surgical septal reduction-although we hope it does.

In any cardiomyopathic process, maintaining as many normally functioning myocytes as possible is clearly desirable, but the evidence that myomectomy significantly impairs overall left ventricular function is slim. In the series mentioned in the editorial, ${ }^{4}$ the evidence for such impairment was a rise in end diastolic diameter from mean of 4.5 to $5.1 \mathrm{~cm}$ over mean follow up of 8.9 years. Fractional shortening wa unchanged $(41 \% \quad v 39 \%)$. The evidence quoted from Spirito et al's study that the natural course of hypertrophic cardiomyopathy is a progressive, inevitable decline in overall left ventricular function, with a consequent reduction in gradient is also no robust: in Spirito's series of patients with severe hypertrophic cardiomyopathy, those who had normal ejection fractions at baseline $(n=54)$ had a mean rise of just $1 \mathrm{~mm}$ in end diastolic diameter over follow up and none developed clinical heart failure. The 13 patients with ejection fractions of less than $50 \%$ had a scarcely impressive rise of $5 \mathrm{~mm}$ in end diastolic diameter, and only one patient in the series had a definite reduction in gradient with time. We cannot rely on time and the natural course of the disease to rid all of our patients of their worrisome and incapacitating left ventricular outflow tract obstruction.

The primary goal in the treatment of hypertrophic cardiomyopathy is clearly the development of strategies known to prolong life and prevent sudden death, but the provision of symptomatic relief for patients can not be ignored. Professor Oakley concludes that "the extreme clinical and genetic heterogeneity of the disease has prevented any prospective randomised trials to assess the effect on outcome of most forms of treat ment". We hope that she recognises that this clinical heterogeneity encompasses a minority of patients with large outflow gradients and corresponding disabling symptoms. We feel our efforts to provide symptomatic relie for this subgroup by means of non-surgical septal reduction are worthwhile, even though the long-term effects on outcome may not be known for many years.

CHARLES KNIGHT
ULRICH SIGWART
Royal Brompton Hospital,
Sydney Street, Lydney Street,

1 Oakley CM. Non-surgical ablation of the ventricular septum for the treatment of hypertrophic cardiomyopathy. $\mathrm{Br}$ Heart $\mathcal{f} 1995$ 74:479-80.

2 Maron BJ, Merrill WH, Freier PA, Kent KM Epstein SE, Morrow AG. Long-term clinical Epstein SE, Momow AG. Long-term clinica course and symptomatic status of patients after operation for hypertrophic su.

3 Sigwart U. Non surgical myocardial reduction for hypertrophic obstrive cardiomyopathy. Lancet 1995;346:211-3.

4 Seiler C, Hess OM, Schoenbeck M, Turina J, Jenni $R$, Turina $M$, et al. Long-term follow- up of medical versus surgical therapy for hypertrophic cardiomyopathy: a retrospective study. F Am Coll Cardiol 1991;17:634-42.

5 Spirito P, Maron BJ, Bonow RO, Epstein SE. Occurrence and sionificance of progressive left ventricular wall thinning and relative cavity dilatation in hypertrophic cardiomyopathy. Am $f$ Cardiol 1987;59:123-9.

This letter was shown to the author, who replies as follows:

SIR,-I thank Dr Knight and Dr Sigwart for summarising my editorial so well in the first paragraph of their letter and of course I agree that progressive decline in overall left ventricular function is not inevitable. Some have mild disease and some die early but others suffer gradual loss of systolic efficiency. Only a small increase in residual volume heralds the onset of low output failure because of the marked diastolic impairmen in these patients whose ventricles do not readily dilate. The natural progression of myocyte fall-out, whether due to the myopathy or to ischaemia, will have been accelerated by "myocardial reduction" in the name of therapy. We shall see.

CELIA M OAKLEY
Hammersmith Hospital,
Du Cane Road,

\section{A wide health remit for aspirin}

SIR,-It is widely recognised that aspirin helps to reduce the risk of certain cardiovascular diseases. More recently, good evidence has indicated that aspirin can also help to reduce the risk of certain gastrointestinal cancers. ${ }^{1}$ I write to ask whether cardiologists who frequently prescribe aspirin have any "dormant" data on the risk of cancer. I am also interested in collaborating with any colleagues who might be conducting randomised trials of aspirin intervention. I would be able to advise on the measurement of wider health gains relating to a reduced risk of cancer.

GARETH MORGAN Pharmaceutical Department West Glamorgan Health Authority, 41 High Street Swansea SA1 $1 L T$

1 Morgan GP. NSAIDs and the chemoprevention of colorectal and oesophageal cancer. tion of colorectal and

\section{NOTICE}

An international workshop on Recent Developments in Cardiac Surgery (video assisted demonstrations on left ventricular reduction and minimally invasive coronary surgery) will be held on the 3 and 4 October 1996 at the Hilton National Hotel, Bristol, United Kingdom. For further information please fax: +44-117-9299737 (Mrs N J Merrell). 